Kristian Knemeyer, Robert Baumgarten, Piyush Ingale, Raoul Naumann d'Alnoncourt, Matthias Driess, Frank Rosowski

\title{
Toolbox for atomic layer deposition process development on high surface area powders
}

Journal article | Published version

This version is available at https://doi.org/10.14279/depositonce-11502

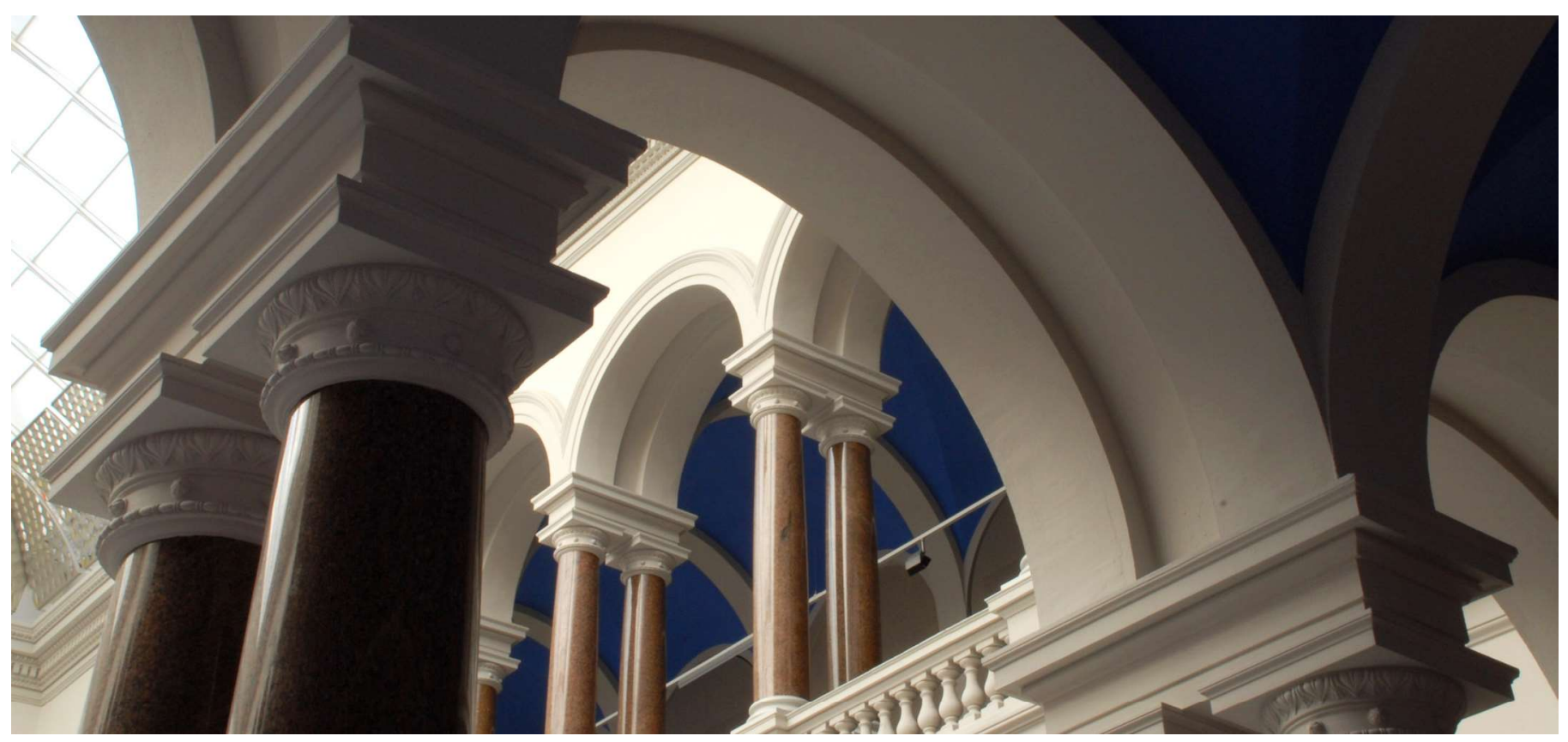

This article may be downloaded for personal use only. Any other use requires prior permission of the author and AIP Publishing. This article appeared in

Knemeyer, K., Baumgarten, R., Ingale, P., Naumann d'Alnoncourt, R., Driess, M., \& Rosowski, F. (2021).

Toolbox for atomic layer deposition process development on high surface area powders. Review of

Scientific Instruments, 92(2), 025115. https://doi.org/10.1063/5.0037844

and may be found at https://doi.org/10.1063/5.0037844. 


\section{Toolbox for atomic layer deposition process development on high surface area powders}

EP

Cite as: Rev. Sci. Instrum. 92, 025115 (2021); https://doi.org/10.1063/5.0037844

Submitted: 16 November 2020 . Accepted: 29 January 2021 . Published Online: 18 February 2021

K. Knemeyer, (i) R. Baumgarten, (i) P. Ingale, (i) R. Naumann d'Alnoncourt, (i) M. Driess, and F. Rosowski

\section{COLLECTIONS}

EP This paper was selected as an Editor's Pick
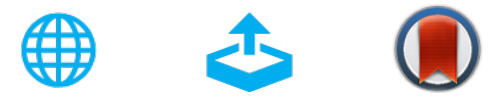

\section{ARTICLES YOU MAY BE INTERESTED IN}

Conformality in atomic layer deposition: Current status overview of analysis and modelling Applied Physics Reviews 6, 021302 (2019); https://doi.org/10.1063/1.5060967

Surface chemistry of atomic layer deposition: A case study for the trimethylaluminum/ water process

Journal of Applied Physics 97, 121301 (2005); https://doi.org/10.1063/1.1940727

Understanding chemical and physical mechanisms in atomic layer deposition

The Journal of Chemical Physics 152, 040902 (2020); https://doi.org/10.1063/1.5133390

\section{Challenge us.}

What are your needs for periodic signal detection?

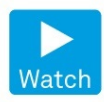

- Zurich

- Instruments

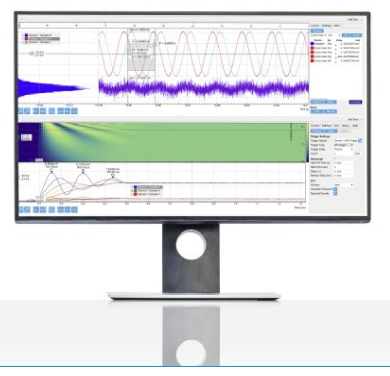

Rev. Sci. Instrum. 92, 025115 (2021); https://doi.org/10.1063/5.0037844

92, 025115 


\title{
Toolbox for atomic layer deposition process development on high surface area powders
}

\author{
Cite as: Rev. Sci. Instrum. 92, 025115 (2021); doi: 10.1063/5.0037844 \\ Submitted: 16 November 2020 - Accepted: 29 January 2021 • \\ Published Online: 18 February 2021
}

\begin{abstract}
K. Knemeyer, ${ }^{7}$ (D) R. Baumgarten, ${ }^{7}$ (D) P. Ingale, ${ }^{7}$ (D) R. Naumann d'Alnoncourt, ${ }^{1, a)}$ (iD M. Driess, ${ }^{1,2}$ and F. Rosowski ${ }^{1,3}$

AFFILIATIONS

'BasCat_UniCat BASF JointLab, Technische Universität Berlin, Hardenbergstraße 36, 10623 Berlin, Germany

${ }^{2}$ Institut für Chemie, Technische Universität Berlin, Straße des 17. Juni 135, 10623 Berlin, Germany

${ }^{3}$ Process Research and Chemical Engineering, BASF SE, Carl-Bosch-Straße 38, 67056 Ludwigshafen, Germany
\end{abstract}

a) Author to whom correspondence should be addressed: r.naumann@bascat.tu-berlin.de

\begin{abstract}
Atomic layer deposition (ALD) is an industrially applied technique for thin film deposition. The vast majority of processes target flat substrates rather than powders. For ALD on powders, new processes are needed, as different reaction conditions are required. Here, two setups are described in detail, which enhance the ALD process development for powders. The first setup described is capable of directly measuring the vapor pressure of a given precursor by a capacitance diaphragm gauge. Promising precursors can be pre-selected, and suitable precursor saturation temperatures can be determined. The second setup consists of four parallel reactors with individual temperature zones to screen the optimal ALD temperature window in a time efficient way. Identifying the precursor saturation temperature beforehand and subsequently performing the first ALD half cycle in the parallel setup at four different reactor temperatures simultaneously will drastically reduce process development times. Validation of both setups is shown for the well-known ALD precursors, trimethylaluminum to deposit aluminum oxide and diethyl zinc to deposit zinc oxide, both on amorphous silica powder.
\end{abstract}

Published under license by AIP Publishing. https://doi.org/10.1063/5.0037844

\section{INTRODUCTION}

Atomic layer deposition (ALD) is a thin film deposition technique capable of coating almost any given material with inorganic layers. ${ }^{1-4}$ The gas solid reaction proceeds in a cyclic fashion in which a precursor is added to the surface and reacts with exposed reactive surface sites until saturation. Subsequent purging of residue precursors and by-products is followed by dosing a reactant to the chemisorbed precursor to form the desired layer and recreating similar reactive surface sites. This procedure can be repeated indefinitely to grow the deposited material layer by layer to the desired thickness. The self-limitation in each so-called half-cycle leads to the precise control of the deposited thickness and excellent reproducibility. ALD has its origin in the microelectronic industry in which most often Si-wafers are coated with elements to tune electric properties. ${ }^{5}$ Over the course of the past 50 years, a wide variety of elements and combinations, thereof, were deposited via ALD. Recently, ALD attracted interest in the field of surface modification of powders, e.g., for drugs, ${ }^{6-8}$ batteries, $^{9-11}$ or catalysts. ${ }^{12-16}$
Several reactor concepts for powders were already developed, ${ }^{17}$ such as fixed bed, ${ }^{18}$ rotary, ${ }^{19}$ or pulsed bed reactors. ${ }^{20}$ Unfortunately, the already developed processes for flat substrates cannot be straightforwardly transferred to powders as additional challenges have to be overcome. Generally, fluidized beds and fixed beds work at a relative high pressure compared to ultra-high vacuum (UHV) processes on flat substrates leading to longer diffusion times. Additionally, the use of plasma or ozone is limited as both tend to recombine readily at contact with a surface, ${ }^{21,22}$ making it impossible to be effective on the bottom fraction of a fixed bed or in highly porous substrates. Furthermore, powders have a larger specific surface area in the order of up to several magnitudes, demanding excellent precursors. The precursor must be reactive toward surface groups while being inert to evolving by-products and must exhibit thermal stability up to the desired process conditions. Most importantly, the precursor must be highly volatile to achieve saturation in reasonable time frames. ${ }^{23}$ Lowly volatile precursors lead to long dosing times and are, therefore, unfeasible for industrial applications. 
Vapor pressure can be determined by thermogravimetric analysis and subsequent calculations based on the Langmuir equation ${ }^{24,25}$ or by directly measuring it with a capacitance manometer. ${ }^{26-28}$ If the necessary vapor pressure cannot be reached below the decomposition temperature, the precursor has to be replaced by a more volatile one. Therefore, pre-selection of suitable precursors for ALD should always be the first step in process development. ${ }^{25,29,30}$ Once suitable vapor pressures and evaporation temperatures are obtained, the reactivity of a precursor should be investigated by quick testing facilities to further reduce process development times. For ALD on flat substrates, a quartz crystal microbalance ${ }^{31}$ or ellipsometer $^{32}$ leads to quick investigations of the growth behavior, but for powders, both techniques are obsolete. Therefore, finding the right combination of precursor, substrate, temperature, pressure, and dosing times is time consuming without proper equipment.

This paper shows two self-designed setups, which tackle the essential challenges of process development on powders.

Vapor pressure determination:

- Direct determination of vapor pressure up to $200^{\circ} \mathrm{C}$ for any given precursor

- Dismiss lowly volatile precursors (vapor pressure < $10 \mathrm{mbar}$ )

- Identify the ideal precursor saturation temperature for maximum molar flow

Parallel deposition:

- Identify precursor reactivity at four different temperatures in parallel

- Determine the ALD window

In combination, both setups lead to time efficient ALD process development on powders in fixed bed reactors. The setups are evaluated by two of the most prominent ALD precursors, trimethylaluminum (TMA) and diethyl zinc (DEZ), of which the vapor pressure curves are measured and reactivity tests on amorphous $\mathrm{SiO}_{2}$ are conducted.

\section{SETUP DESIGN}

Both setups are operated separately and are described in detail in Secs. II A and II B with their respective flow charts (Figs. 1 and 2). However, both setups are located within a closed cabinet of polycarbonate windows embedded in aluminum profiles. They share a common ventilation to evacuate possible evolving gases.

\section{A. Vapor pressure determination}

\section{Precursor}

The precursor chamber consists of a quartz reservoir $(5 \mathrm{~cm}$ height $\times 2 \mathrm{~cm}$ inner diameter) with a KF16 flange connected to a $\frac{1}{4}$ ” bellow valve (Swagelok ${ }^{\circledR}$ ). The precursor is filled inside a glovebox or in air, respectively, depending on its air stability. Prior to the vapor pressure determination the residual gas atmosphere has to be completely removed so that the resulting pressure is the result of the precursor's vapor pressure. This is realized by three consecutive cycles of freezing the precursor in liquid nitrogen, evacuating the precursor chamber, and then thawing the precursor. This can be done conveniently by the Schlenk technique. Subsequently, the precursor chamber is connected to the setup by VCR connections (Swagelok ${ }^{\circledR}$ ).

\section{Heating}

Heating of the precursor is realized by an oven (Salvislab Thermocenter TC100) in which the precursor and all affected dosing lines (stainless steel) are located. Having one heating zone prevents cold spot formation and with that undesired condensation of the precursor. The oven can be operated up to $200^{\circ} \mathrm{C}$, and step wise temperature programs can be carried out.

\section{Measurement cell}

The measurement cell consists of a capacitance manometer (MKS Baratron ${ }^{\circledR}$ Type 631) with a control device (MKS Instruments, PDR2000 dual capacitance diaphragm gauge controller), which displays the pressure measured by the capacitance diaphragm gauge. The measuring principle is based on the distance between a diaphragm and a reference electrode, together serving as a capacitor. The diaphragm is exposed on one side to vacuum and on the other side to the sample pressure. It deflects depending on the present pressure changing the distance to the electrode and with that the capacitance. The capacitance is, therefore, correlated with the pressure in the system. The control device precisely measures the $0 \mathrm{~V}$ $-10 \mathrm{~V}$ signal from the capacitance manometer to cover the full range from 0.1 Torr $(0.13 \mathrm{mbar})$ to 1000 Torr $(1300 \mathrm{mbar})$. The data are logged by reading the analog output with a data logger (Picolog TC-08 Thermocouple logger) and are then processed with a personal computer. To prevent any condensation on the diaphragm, the capacitance manometer is internally heated up to $200^{\circ} \mathrm{C}$.

\section{Downstream}

Evacuation of the system is realized by two pumps. One is a rotary vane pump (Pfeiffer Vacuum, DUO 5) for a vacuum down to $3 \times 10^{-3}$ mbar, which is used for evacuating the system. The second pump is a turbo molecular pump (Pfeiffer Vacuum, HighPace ${ }^{\circledR}$ 80) and is used whenever the baratron needs to be zeroed before the measurement, as the turbo molecular pump reaches pressures below the full range of the baratron. To prevent the exposure of precursor to the pumps, a liquid nitrogen cooling trap is installed between the pumps and the rest of the system. The system can be flushed with nitrogen (99.999\%) to purge residues away. To prevent damage to the baratron by pressures exceeding 1 bar, an overflow valve is installed in the nitrogen line, which releases pressures above 1 bar. $^{86,87}$

\section{B. Parallel deposition setup}

\section{Reactors}

The reactors consist of borosilicate glass (Duran ${ }^{\circledR}$ ) tubes with an inner diameter of $3 \mathrm{~mm}$, a wall thickness of $2.5 \mathrm{~mm}$, and a length of $7 \mathrm{~cm}$. At the lower third, a narrowing serves as a ledge for quartz wool on which the powder can be filled $(0.1 \mathrm{ml})$. The bottom and top parts of the tube each contain a KF16 flange connected on the top side to a bellow valve and on the bottom end to the precursor reservoir and subsequently to an additional bellow valve. The valves allow the assembly of substrate and precursor under inert conditions 
inside a glovebox. The precursor reservoir is made of borosilicate glass to visualize the precursor level. The precursor dosing is realized by overflowing the precursor with nitrogen.

\section{Heating}

Heating is realized in two heating zones. Heating zone 1 is regulated by an oven (Salvislab Thermocenter TC100), which is responsible for heating all precursors simultaneously. Furthermore, it heats all stainless steel tubes and walls, which are in contact with the precursor to prevent cold spots and, therefore, condensation. Heating zone 1 has generally the same or lower temperature than heating zone 2. Heating zone 2 consists of individual heating jackets (Winkler, custom made) for each reactor. It can be adjusted by a temperature controller (Winkler, W-200 series) from room temperature to $400{ }^{\circ} \mathrm{C}$ to allow different temperatures to be screened in parallel. The heating jacket itself resists up to $200^{\circ} \mathrm{C}$ from outer heating, which allows the heating zone 1 to be operated up to $200^{\circ} \mathrm{C}$. Note that the set point of the heating jacket is considered as substrate temperature, and blank experiments showed a negligible temperature offset.

\section{Gas supply}

The gas supply consists of synthetic air (99.999\%) and nitrogen (99.999\%) of which either is dosed to the reactor selected by a threeway valve. The selected gas is distributed into four lines, leading to a manual needle valve (Swagelok, $100 \mathrm{ml} / \mathrm{min}$ ) for each reactor. An overflow valve prevents damage to the glass equipment and needle valves, as pressures over 1 bar are released.

\section{EXPERIMENTAL}

TMA and DEZ are both intensively studied ALD precursors and will, therefore, be used as reference systems to evaluate the setups. Their vapor pressures were measured and compared to the literature for validation of the vapor pressure setup. Additionally, vapor pressures of metal acetylacetonates were measured and provided. Deposition experiments of TMA and DEZ on amorphous $\mathrm{SiO}_{2}$ were conducted at different temperatures to validate the parallel deposition setup.

\section{A. Chemicals}

Silica powder $\left[\mathrm{SiO}_{2}\right.$, high-purity grade $\geq 99 \%$ (Davisil Grade 636), average pore size $60 \AA$, 35-60 mesh particle size, Sigma-Aldrich, specific surface area $505 \mathrm{~m}^{2} \mathrm{~g}^{-1}$ ] was used as a substrate. Trimethylaluminum $\left[\mathrm{Al}\left(\mathrm{CH}_{3}\right)_{3}\right.$, TMA, elec. gr., 99.999\% Al], diethyl zinc $\left[\mathrm{Zn}\left(\mathrm{C}_{2} \mathrm{H}_{5}\right)_{2}, \mathrm{DEZ}\right.$, elec. gr., $99.999 \%$ $\mathrm{Zn}$, Strem Chemicals $\mathrm{GmbH}$, manganese(III) acetylacetonate (Sigma-Aldrich, technical grade), chromium(III) acetylacetonate (Sigma-Aldrich, 99.99\%), Iron(III) acetylacetonate (abcr, 95\%), nickel(II) acetylacetonate (Sigma-Aldrich, 95\%), copper(II) acetylacetonate (Sigma-Aldrich, 97\%), cobalt(II) acetylacetonate (SigmaAldrich, 97\%), vanadium(III) acetylacetonate (Sigma-Aldrich, 97\%), cobalt(III) acetylacetonate (Sigma-Aldrich, 99.99\%), and water $\left(\mathrm{H}_{2} \mathrm{O}, \mathrm{CHROMASOLV}^{\circledR}\right.$, for HPLC, Riedel-de Haën) served as precursors and were used without further purification. High purity $\mathrm{N}_{2}$ and synthetic air (99.999\%) were used as carrier and purging gases.

\section{B. Experimental-Vapor pressure determination}

The metal organic precursor $(1 \mathrm{ml})$ was inserted in the precursor chamber under inert conditions inside a glovebox. The precursor chamber was then transferred from the glovebox to a Schlenk line by connecting it via the bellow valve. The precursor was frozen in liquid nitrogen, and the excessive atmosphere was removed by a rotary pump and subsequently thawed at room temperature. This cycle was repeated three times to remove the residual glovebox atmosphere. The precursor chamber was then assembled to the setup inside the oven. Then, the setup was evacuated by the rotary vane pump followed by flushing of nitrogen. This was repeated up to three times to make sure no residue air or adsorbates remain inside the lines. The system was then evacuated to pressures below the full range of the capacitance manometer by using the turbo molecular pump followed by zeroing the manometer. The precursor and setup walls were heated to the desired starting temperature by the oven. After temperature stabilization, the bellow valve of the precursor chamber was opened and the precursor was released into the system where the pressure was constantly measured and recorded. This pressure equals directly to the vapor pressure of the precursor. The temperature was then increased stepwise until the desired maximum temperature was reached. For each temperature step, sufficient long stabilization time should be realized to reach thermal equilibrium. After reaching the maximum temperature and measuring the resulting vapor pressure, the bellow valve of the precursor chamber was closed and the system was then evacuated. The last step was flushing with $\mathrm{N}_{2}$ to remove the precursor. The cooling trap was then disassembled, and the frozen precursor was quenched.

\section{Experimental-Parallel deposition}

The reactors were assembled in the glovebox under inert conditions, allowing the substrate and the precursor to be free of unwanted adsorbates such as water. The glass tube was filled with a thin layer of quartz wool on which the substrate $\left(\mathrm{SiO}_{2}, 0.1 \mathrm{ml}\right)$ was deposited. The top part of the reactor was then connected to a closed bellow valve. The precursor vessel was filled with the respective precursor and connected to the bottom end of the reactor, which contains a closed bellow valve. This was done individually for up to four reactors, which were then transferred from the glovebox to the setup. Reactors were assembled to the setup by connecting the bottom valve to the gas supply and the top valve to the exhaust line. Heating jackets were attached and set to the desired temperatures. For DEZ, the set temperatures were $50^{\circ} \mathrm{C}, 80^{\circ} \mathrm{C}, 100^{\circ} \mathrm{C}$, and $120^{\circ} \mathrm{C}$, and for TMA, the set temperatures were $30^{\circ} \mathrm{C}, 80^{\circ} \mathrm{C}, 150{ }^{\circ} \mathrm{C}$, and $200^{\circ} \mathrm{C}$, respectively. Nitrogen served as carrier gas for the precursor, and the four needle valves were set to $20 \mathrm{ml} / \mathrm{min}$. The bellow valve on the top of the reactor was then opened followed by the bellow valve on the bottom. The precursor was flowing through the substrate from the bottom to the top without fluidizing it. After a certain reaction time, the precursor was fully evaporated and transported through the substrate bed. Once this was observed and sufficient long $\mathrm{N}_{2}$ dosing time passed, synthetic air was dosed by switching the three-port valve. This allows air-sensitive chemisorbed precursors to react in a controlled environment before exposing it to air. Afterward, all heaters were turned off, the bellow valves were closed, and the reactors were disassembled. The substrates were then chemically analyzed either by x-ray fluorescence spectroscopy (XRF, Bruker S4 


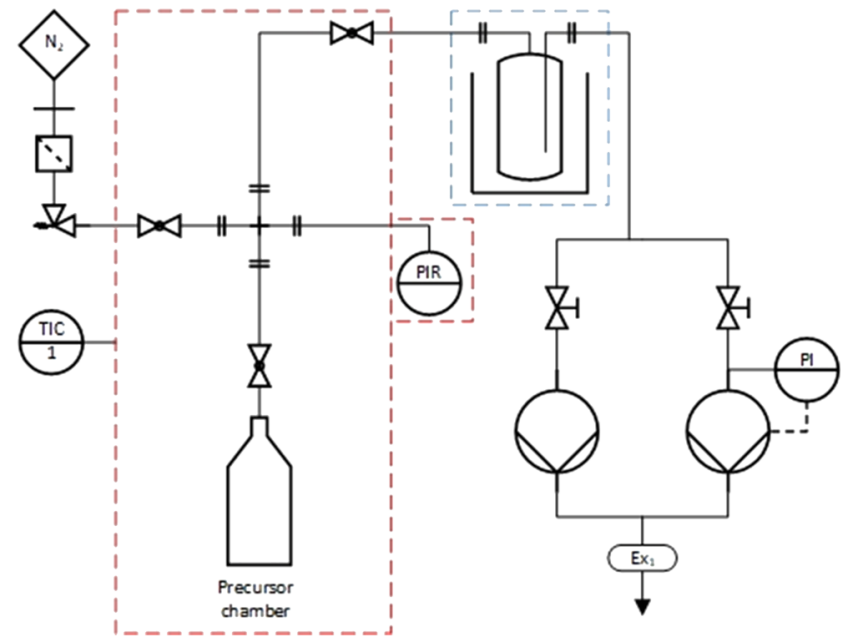

FIG. 1. Flow chart of the vapor pressure determination setup $(T I C=$ temperature indicator controller, $\mathrm{PIR}$ = pressure indicator recorder, and $\mathrm{PI}$ = pressure indicator).

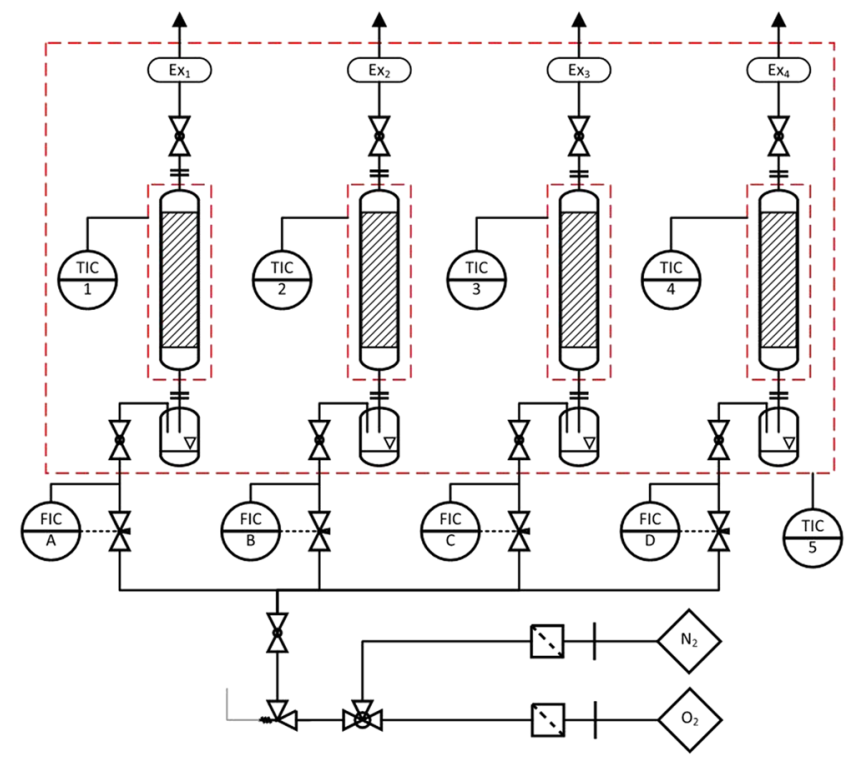

FIG. 2. Flow chart of the parallel deposition setup $(T I C=$ temperature indicator controller and FIC = flow indicator controller).

Pioneer x-ray spectrometer) or inductively coupled plasma-optical emission spectroscopy (ICP-OES; Varian 720-ES) to determine the deposited amount of $\mathrm{Al}$ and Zinc, respectively (Figs. 1 and 2).

\section{RESULTS AND DISCUSSION}

\section{A. Vapor pressure determination}

The main goal of determining the vapor pressure of a given precursor is to estimate its value for an ALD process. For flat substrates, a minimum vapor pressure of 1 mbar is suggested to be necessary for a feasible process. ${ }^{24,33}$ For powder coating, we suggest a minimum vapor pressure of $10 \mathrm{mbar}$, as the total surface areas are orders of magnitudes higher. Therefore, precursors with a vapor pressure below 10 mbar at elevated temperatures should be dismissed and alternative precursors must be developed or obtained. The vapor pressures of TMA, DEZ, and water were measured in the range of $40^{\circ} \mathrm{C}-100{ }^{\circ} \mathrm{C}$ with $10^{\circ} \mathrm{C} /$ step and compared to the literature (Fig. 3). ${ }^{34,35}$

The measured vapor pressures are in very good agreement with the literature especially for lower vapor pressures (Table I). DEZ, TMA, and water exceed the desired vapor pressure of $10 \mathrm{mbar}$ already at room temperature, showing ideal volatilities for ALD. They are not only reactive and stable but also have a very high vapor pressure. As the saturation time of the ALD process scales linearly with the molar flow of the precursor, it is advised to use precursor temperatures, which are as high as possible but below decomposition temperature and safe according to the installed precautions. For example, using TMA at $60^{\circ} \mathrm{C}$ instead of $40^{\circ} \mathrm{C}$ already doubles the vapor pressure and, therefore, decreases cycle times by half (Table I).

Exemplarily, vapor pressures of several metal acetylacetonates were determined to demonstrate the capability of the setup also for lowly volatile precursor (Fig. 4).

It can be seen that the measured vapor pressures are below $10 \mathrm{mbar}$ in the temperature range below $90^{\circ} \mathrm{C}$ for all precursor except $\mathrm{Mn}(\mathrm{acac})_{3}$ and $\mathrm{Cr}(\mathrm{acac})_{2}$. Even at $100^{\circ} \mathrm{C}, \mathrm{Co}(\mathrm{acac})_{2}$ and $\mathrm{Co}(\mathrm{acac})_{3}$ barely reach $10 \mathrm{mbar}$ and $\mathrm{Cu}(\mathrm{acac})_{2}$ is even less volatile with a vapor pressure below 10 mbar. Therefore, the metal acetylacetonate precursors can only be relevant for ALD at atmospheric pressure on powders if precursor temperatures of $100^{\circ} \mathrm{C}$ can be realized. To still utilize metal acetylacetonates, the precursor chamber should be operated at pressures below the determined vapor pressure to increase the evaporation rate. The vapor pressure curves show the importance of the setup, as pre-selections of suitable precursors can and must be made. This reduces process development time drastically, as trying to develop a process with a non-volatile precursor is set up for failure and waste of time. Additionally, precursor classes can be systematically correlated with vapor pressures, allowing accurate predictions in the future, reducing ALD process development times even more. Once the ideal precursor temperature is determined, it will be transferred and tested on its reactivity at varying temperatures in the parallel deposition setup.

\section{B. Parallel deposition}

For atomic layer deposition, it is crucial to determine the socalled ALD window. It is the temperature range in which the growth reaches self-limitation within a temperature range despite excess of precursor. Below the ALD window, condensation and/or no reaction occurs; above the ALD window, decomposition and/or desorption can occur, both leading to non-ALD growth behavior. ${ }^{1}$ Typically, the non-ideal growth behavior can almost exclusively be attributed to the metal organic precursor dosing, as decomposition or side reactions occur more readily with metal organics than with typical co-reactants (e.g., $\mathrm{H}_{2} \mathrm{O}, \mathrm{O}_{2}$, or $\mathrm{H}_{2}$ ). Therefore, investigating the very first half cycle, the reaction between metal organic precursor and reactive surface sites, should reveal the ALD window. The parallel deposition setup can be exploited to determine the said ALD 

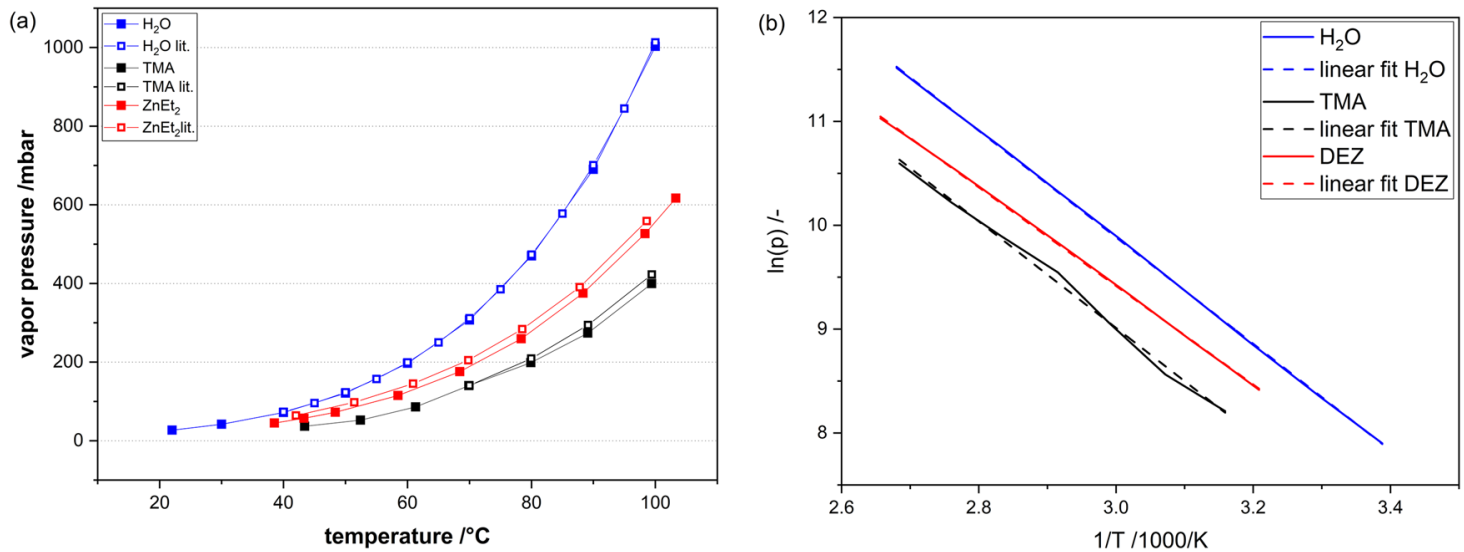

FIG. 3. (a) Measured vapor pressures of TMA, DEZ, and water at varying temperatures compared to their respective literature ${ }^{34,35}$ and (b) the resulting linear ClausiusClapeyron plots.

window as shown for the well-studied precursors TMA and DEZ, both on amorphous $\mathrm{SiO}_{2}$. To make sure saturation of the surface by precursor is achievable, excessive amounts of precursor were provided for each experiment. Four different temperatures were screened for each process, and subsequent chemical analysis (XRF or ICP-OES) reveals the amount of deposited central metal atom on the surface (Fig. 5).

The $\mathrm{Al}$ system reveals a temperature window from $30^{\circ} \mathrm{C}$ to $200{ }^{\circ} \mathrm{C}$ (Fig. 5) on $\mathrm{SiO}_{2}$ in which ideal deposition of aluminum among the surface at all screened temperatures occurs. The determined temperature window is only a fraction of the full ALD window, which was not determined in this work, as the parallel deposition setup already reveals reaction conditions in which ideal ALD can be conducted. The deposited $\mathrm{Al}$ amount at all temperatures is 7 wt. $\%$ and translates into $3 \mathrm{Al} / \mathrm{nm}^{2} .2$ Correlating the aluminum surface concentration with the surface hydroxyl group density of $3.5 \mathrm{OH} / \mathrm{nm}^{2}$ shows that less than a monolayer of aluminum is deposited in the first half cycle, which is in agreement with the literature. ${ }^{1,36}$ The ALD window of TMA is barely reported, as TMA basically always works in a very broad range of temperatures up to $300{ }^{\circ} \mathrm{C}$ on varying substrates (Fig. 6). The process temperature is often limited by the thermal stability of the substrate, by the deposition system itself, or by the choice of reactant.

TABLE I. Fitting parameters (slope of fitting, $R^{2}=$ coefficient of determination), calculated evaporation enthalpies, and respective literature values for water, TMA, and DEZ.

\begin{tabular}{lcccc}
\hline \hline Precursor & $\begin{array}{c}\text { Slope of } \\
\text { fitting (K) }\end{array}$ & $\mathrm{R}^{2}(-)$ & $\begin{array}{c}\Delta_{\text {vap }} \mathrm{H} \\
(\mathrm{kJ} / \mathrm{mol})\end{array}$ & $\begin{array}{c}\Delta_{\text {vap }} \mathrm{H}_{\text {lit. }} \\
(\mathrm{kJ} / \mathrm{mol})\end{array}$ \\
\hline $\mathrm{H}_{2} \mathrm{O}$ & -5128.16 & 0.99994 & 42.64 & $42.96^{34}$ \\
$\mathrm{TMA}$ & -5127.14 & 0.99584 & 42.63 & $43.00^{34}$ \\
$\mathrm{DEZ}$ & -4746.21 & 0.99987 & 39.46 & $39.90^{35}$ \\
\hline \hline
\end{tabular}

The $\mathrm{Zn}$ system reveals an ALD window between $50^{\circ} \mathrm{C}$ and $80^{\circ} \mathrm{C}$ above which a substantial loss of $\mathrm{Zn}$ content occurs (Fig. 5). Decreased mass at elevated temperatures indicates desorption phenomena, leading to an effective by-pass of unreacted precursor. ${ }^{56}$ The literature shows similar trends but with varying temperature windows. ${ }^{56-62,86,87}$ Despite the relative low and narrow ALD window, the determined $\mathrm{ZnO}$ loadings of the parallel deposition experiments at $80^{\circ} \mathrm{C}(12 \mathrm{wt} . \% \mathrm{Zn})$ match the experimental data of previously published $\mathrm{ZnO}$ studies (12.5 wt. \% $\mathrm{Zn}){ }^{63}$ As for $\mathrm{Al}$, the $\mathrm{Zn}$ surface concentration can be calculated and correlated with the surface hydroxyl group density. For the DEZ deposition at $80^{\circ} \mathrm{C}$, the $\mathrm{Zn}$ concentration is $2.1 \mathrm{Zn} / \mathrm{nm}^{2}$ and with that only $63 \%$ of the $\mathrm{OH}$ groups might be covered. We investigated the self-limiting behavior

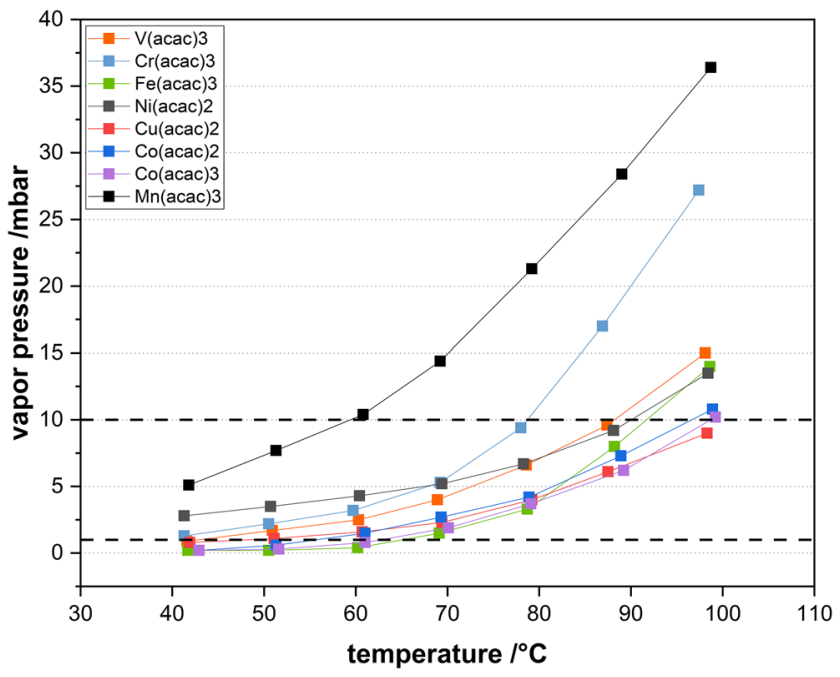

FIG. 4. Measured vapor pressures of metal acetylacetonates from $40^{\circ} \mathrm{C}$ to $100^{\circ} \mathrm{C}$. 

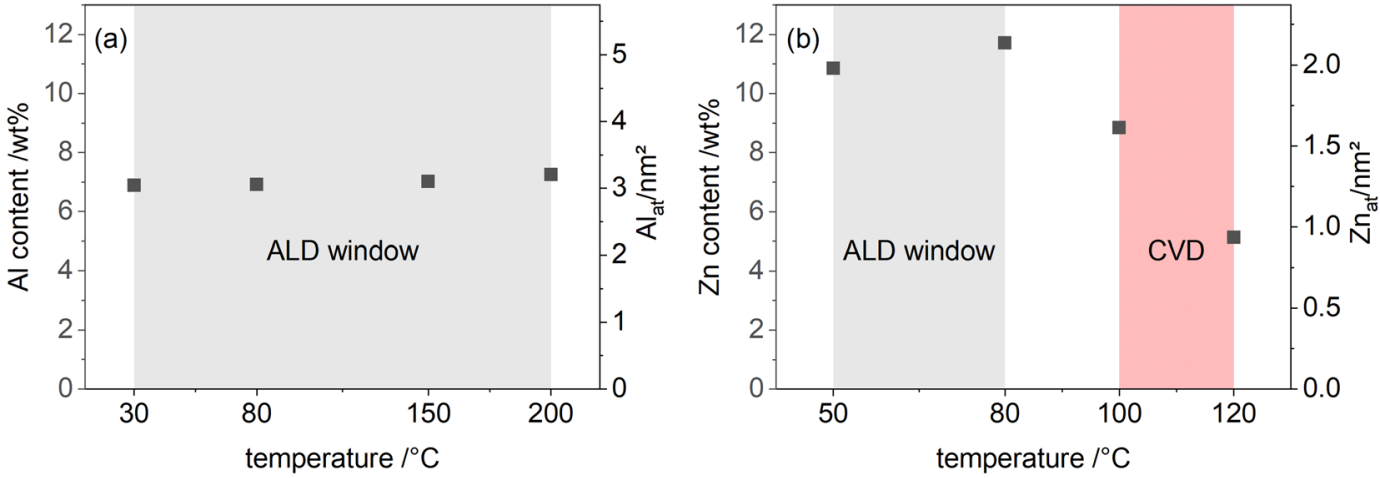

FIG. 5. Shown is (a) the Al loading determined by XRF, calculated surface density at different temperature and the indicated ALD window and (b) the $\mathrm{Zn}$ loading determined by ICP-OES, calculated surface density at different temperatures, the indicated ALD window, and the non-ideal deposition window.

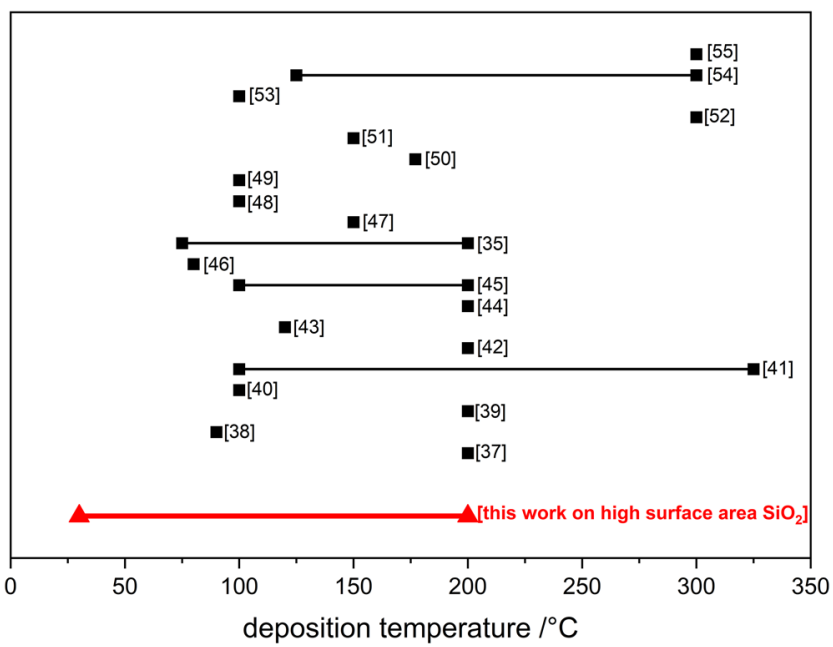

FIG. 6. ALD windows of TMA according to the selected literature and our determined ALD window on high surface area amorphous $\mathrm{SiO}_{2} \cdot{ }^{35,37-55}$

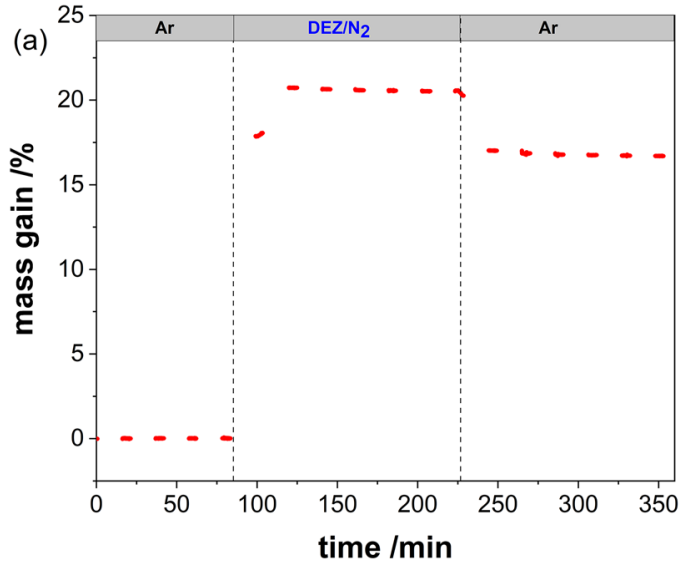

of the DEZ deposition in a magnetic suspension balance as part of a previous study. The magnetic suspension balance is a setup on its own and not part of the setups discussed here. However, the balance can confirm self-limitation of the growth behavior via in situ measurement of the mass gain. The balance confirmed for DEZ deposition on $\mathrm{SiO}_{2}$ self-limitation at $80^{\circ} \mathrm{C}$ [Fig. $\left.7(\mathrm{a})\right]^{63}$ and the absence of self-limitation at $150^{\circ} \mathrm{C}$ [Fig. 7(b)]. The DEZ deposition at $150^{\circ} \mathrm{C}$ shows a rapid increase in mass gain once the atmosphere is switched from Ar to DEZ. However, further precursor dosing leads to a continuous mass gain. The absence of self-limitation is a strong indication of decomposition and combined with the observed decrease in Zn loading above $80^{\circ} \mathrm{C}$ in our parallel deposition setup, leading to the conclusion that desorption and decomposition occur in parallel at high temperatures on powders. These findings are supported by a kinetic model published by Muneshwar and Cadien in 2018 .

Comparing our work with the literature shows that $\mathrm{ZnO}$ ALD on powders can be conducted at low temperatures of $80^{\circ} \mathrm{C}$, as shown by Di Mauro et al. on poly(methyl methacrylate) (PMMA) powder. ${ }^{88}$ A comparison with flat substrates shows that the determined ALD window is, in general, lower for powders than for flat substrates (Fig. 8). Even there, the literature reported ALD window ranges are

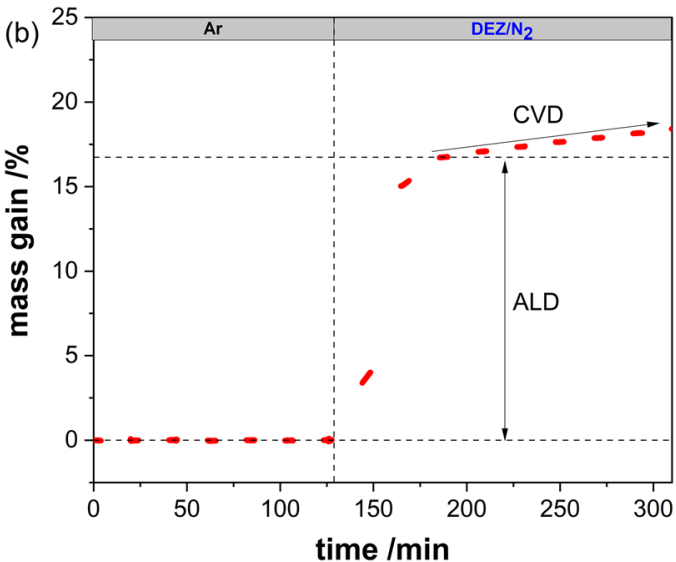

FIG. 7. Mass gain over time in a magnetic suspension balance for $\mathrm{DEZ}$ exposure to amorphous $\mathrm{SiO}_{2}$ with the dosing sequences indicated at the top. Ar was used as purging gas before the reaction and DEZ diluted in $\mathrm{N}_{2}$ served as a precursor. (a) Shown is the first half cycle at $80^{\circ} \mathrm{C}$ in which self-limitation is observed. Switching from the DEZ precursor diluted in $\mathrm{N}_{2}$ to Ar for purging results in an apparent mass loss due to buoyancy. (b) Shown is the first half cycle at $150^{\circ} \mathrm{C}$ in which no self-limitation is observed. 


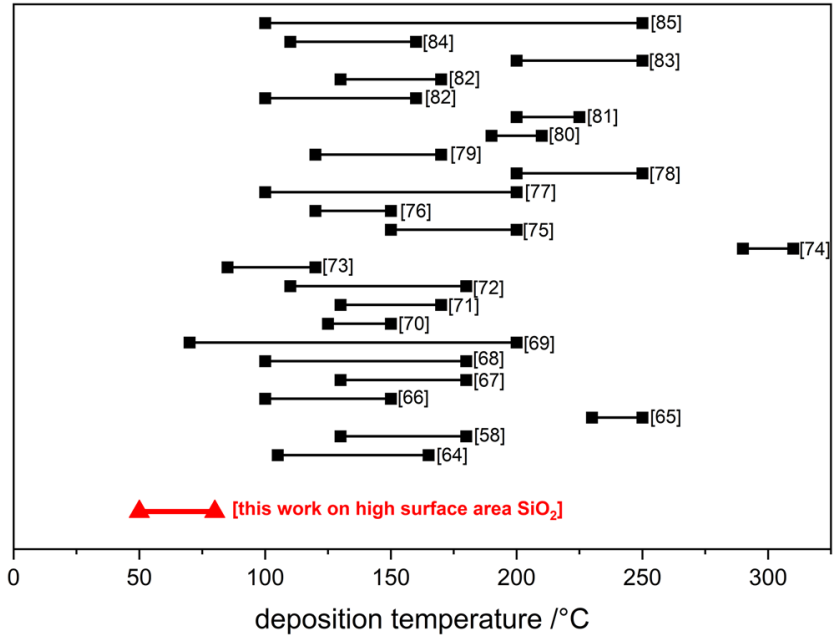

FIG. 8. ALD windows of diethylzinc (DEZ) on almost exclusively flat substrates according to the literature compiled in a review by Karppinen et al. and our determined ALD window on high surface area amorphous $\mathrm{SiO}_{2}$.

inconsistent despite using the same precursor, DEZ. The deposition temperature might vary depending on the substrate, reactor geometry, and pressure during the reaction. Furthermore, the desired deposition temperature also depends on the desired crystal structure as lower temperatures of $80^{\circ} \mathrm{C}$ lead to most less ordered, noncrystalline $\mathrm{ZnO}$ films, ${ }^{63}$ whereas higher temperatures above $200^{\circ} \mathrm{C}$ lead to crystalline $\mathrm{ZnO}$ films. ${ }^{89}$

Ultimately, the parallel deposition setup shows for the most ideal ALD precursor, TMA, to be in complete agreement with the literature. However, conducting experiments with another well investigated precursor DEZ, which is described in the literature as an ideal and easy to deposit precursor, ${ }^{65}$ reveal clear deviation in the ALD window on powders compared to flat substrates. This clearly shows that processes developed on flat substrates cannot be straightforwardly transferred to powders. Thus, the importance of a time efficient testing facility for powders is undeniable.

\section{SUMMARY AND CONCLUSIONS}

In this paper, two setups were developed and constructed for time efficient ALD process development on powders in fixed bed reactors. The first setup is capable of directly measuring the vapor pressure of a given precursor with a capacitance manometer. It allows pre-selection of ALD precursors based on their vapor pressure. Precursors with vapor pressures above $10 \mathrm{mbar}$ at a certain temperature will be considered as promising for ALD on powders. The setup is validated by measuring the vapor pressure of TMA, $\mathrm{DEZ}$, and water in the range of $30^{\circ} \mathrm{C}-100^{\circ} \mathrm{C}$, and the results are in excellent agreement with the literature. In addition, vapor pressures of several metal acetylacetonates were determined in the range of $40^{\circ} \mathrm{C}-100^{\circ} \mathrm{C}$, and it was shown that most of them are not volatile enough for ALD. The second setup consists of four parallel reactors in which the deposition temperatures were screened at four different temperatures in parallel to determining the ALD window. The parallel deposition setup was successfully evaluated using aluminum oxide and zinc oxide deposition on amorphous $\mathrm{SiO}_{2}$ as prime examples. DEZ deposition on $\mathrm{SiO}_{2}$ powder revealed clear deviation to the reported literature on flat substrates, as the resulting ALD window was below all other reported ones. This shows the need for a toolbox for ALD process development on high surface area powders. Combining these two setups allows effective and time efficient process development for ALD on powders and will be used to access more ALD processes on powders in the future.

\section{ACKNOWLEDGMENTS}

The work was conducted in the framework of the BasCatUniCat BASF JointLab at the Technical University of Berlin. The work was partially funded by the Deutsche Forschungsgemeinschaft (DFG, German Research Foundation) under Germany's Excellence Strategy-Grant No. EXC 2008-390540038-UniSysCat. The authors thank Stephen Lohr (BASF), Iris Pieper (TU Berlin, ICPOES), and Olaf Timpe (Fritz-Haber-Institute, XRF).

\section{DATA AVAILABILITY}

The data that support the findings of this study are available within the article.

\section{REFERENCES}

${ }^{1}$ R. L. Puurunen, J. Appl. Phys. 97, 121301 (2005).

${ }^{2}$ S. M. George, Chem. Rev. 110, 111-131 (2010).

${ }^{3}$ B. J. Oneill, D. H. K. Jackson, J. Lee, C. Canlas, P. C. Stair, C. L. Marshall, J. W. Elam, T. F. Kuech, J. A. Dumesic, and G. W. Huber, ACS Catal. 5, 1804-1825 (2015).

${ }^{4}$ M. Leskelä and M. Ritala, Angew. Chem., Int. Ed. 42, 5548-5554 (2003).

${ }^{5}$ G. N. Parsons, J. W. Elam, S. M. George, S. Haukka, H. Jeon, W. M. M. (E.). Kessels, M. Leskelä, P. Poodt, M. Ritala, and S. M. Rossnagel, J. Vac. Sci. Technol., A 31, 050818 (2013).

${ }^{6}$ R. J. Narayan, N. A. Monteiro-Riviere, R. L. Brigmon, M. J. Pellin, and J. W. Elam, JOM 61, 12-16 (2009).

${ }^{7}$ J. Hellrup, M. Rooth, E. Mårtensson, K. Sigfridsson, and A. Johansson, Eur. J. Pharm. Biopharm. 140, 60-66 (2019).

${ }^{8}$ T. O. Kääriäinen, M. Kemell, M. Vehkamäki, M.-L. Kääriäinen, A. Correia, H. A. Santos, L. M. Bimbo, J. Hirvonen, P. Hoppu, S. M. George, D. C. Cameron, M. Ritala, and M. Leskelä, Int. J. Pharm. 525, 160-174 (2017).

${ }^{9}$ B. Yan, X. Li, Z. Bai, X. Song, D. Xiong, M. Zhao, D. Li, and S. Lu, J. Power Sources 338, 34-48 (2017).

${ }^{10}$ H. C. M. Knoops, M. E. Donders, M. C. M. van de Sanden, P. H. L. Notten, and W. M. M. Kessels, J. Vac. Sci. Technol., A 30, 010801 (2012).

${ }^{11}$ X. Meng, X.-Q. Yang, and X. Sun, Adv. Mater. 24, 3589-3615 (2012).

${ }^{12}$ S. C. Riha, B. M. Klahr, E. C. Tyo, S. Seifert, S. Vajda, M. J. Pellin, T. W. Hamann, and A. B. F. Martinson, ACS Nano 7, 2396-2405 (2013).

${ }^{13}$ N. Cheng, M. N. Banis, J. Liu, A. Riese, X. Li, R. Li, S. Ye, S. Knights, and X. Sun, Adv. Mater. 27, 277-281 (2015).

${ }^{14}$ V. E. Strempel, D. Löffler, J. Kröhnert, K. Skorupska, B. Johnson, R. N. d'Alnoncourt, M. Driess, and F. Rosowski, J. Vac. Sci. Technol., A 34, 01A135 (2016).

${ }^{15}$ K. Knemeyer, M. Piernavieja Hermida, P. Ingale, J. Schmidt, J. Kröhnert, R. Naumann d'Alnoncourt, M. Driess, and F. Rosowski, Phys. Chem. Chem. Phys. 32, 17999-18006 (2020). 
${ }^{16}$ P. Ingale, C. Guan, R. Kraehnert, R. Naumann d'Alnoncourt, A. Thomas, and F. Rosowski, Catal. Today 362, 47-54 (2020).

${ }^{17}$ D. Longrie, D. Deduytsche, and C. Detavernier, J. Vac. Sci. Technol., A 32, 010802 (2014).

${ }^{18}$ V. E. Strempel, R. Naumann d'Alnoncourt, M. Driess, and F. Rosowski, Rev. Sci. Instrum. 88, 074102 (2017).

${ }^{19}$ J. A. McCormick, B. L. Cloutier, A. W. Weimer, and S. M. George, J. Vac. Sci. Technol., A 25, 67-74 (2007).

${ }^{20}$ H. Tiznado, D. Domínguez, F. Muñoz-Muñoz, J. Romo-Herrera, R. Machorro, O. E. Contreras, and G. Soto, Powder Technol. 267, 201-207 (2014).

${ }^{21}$ P. Schindler, M. Logar, J. Provine, and F. B. Prinz, Langmuir 31, 5057-5062 (2015).

${ }^{22}$ U. Cvelbar, M. Mozetic, and A. Ricard, IEEE Trans. Plasma Sci. 33, 834-837 (2005).

${ }^{23}$ C. B. Musgrave and R. G. Gordon, Futur. Fab Int. 18, 126-128 (2005).

${ }^{24}$ M. Land, K. Roberston, and S. Barry, chemRxiv 9413573.

${ }^{25}$ G. V. Kunte, S. A. Shivashankar, and A. M. Umarji, Meas. Sci. Technol. 19, 025704 (2008)

${ }^{26}$ S. A. Rushworth, L. M. Smith, A. J. Kingsley, R. Odedra, R. Nickson, and P. Hughes, Microelectron. Reliab. 45, 1000-1002 (2005).

${ }^{27}$ R. F. Berg, J. Chem. Eng. Data 60, 3483-3495 (2015).

${ }^{28}$ M. J. S. Monte, L. M. N. B. F. Santos, M. Fulem, J. M. S. Fonseca, and C. A. D. Sousa, J. Chem. Eng. Data 51, 757-766 (2006).

${ }^{29}$ I. K. Igumenov, T. V. Basova, V. R. Belosludov, and M. Tadashi, "Volatile precursors for films deposition: Vapor pressure, structure and thermodynamics," Application of Thermodynamics to Biological and Materials Science (IntechOpen, 2011), Chap. 20.

${ }^{30}$ G. Fang, L. Xu, Y. Cao, and A. Li, Coord. Chem. Rev. 322, 94-103 (2016).

${ }^{31}$ D. J. Hagen, M. E. Pemble, and M. Karppinen, Appl. Phys. Rev. 6, 041309 (2019).

${ }^{32}$ S. Kim, S. Lee, S.-Y. Ham, D.-H. Ko, S. Shin, Z. Jin, and Y.-S. Min, Appl. Surf. Sci. 469, 804-810 (2019).

${ }^{33}$ M. Griffiths, Z. Dubrawski, P. Gordon, M. Junige, and S. Barry, chemRxiv 13077386.v1.

${ }^{34}$ M. Fulem, K. Růžička, V. Růžička, E. Hulicius, T. Šimeček, K. Melichar, J. Pangrác, S. A. Rushworth, and L. M. Smith, J. Cryst. Growth 248, 99-107 (2003). ${ }^{35}$ D. R. Stull, Ind. Eng. Chem. 39, 517-540 (1947).

${ }^{36}$ V. Strempel, K. Knemeyer, R. Naumann d'Alnoncourt, M. Driess, and F. Rosowski, Nanomaterials 8, 365 (2018).

${ }^{37}$ M. Snelgrove, C. McFeely, P. G. Mani-Gonzalez, K. Lahtonen, R. Lundy, G. Hughes, M. Valden, E. McGlynn, P. Yadav, J. Saari, M. A. Morris, and R. O’Connor, Appl. Surf. Sci. 515, 145987 (2020).

${ }^{38}$ W. Wang, Y. Yuan, J. Wang, Y. Zhang, C. Liao, X. Mu, H. Sheng, Y. Kan, L. Song, and Y. Hu, ACS Appl. Energy Mater. 2, 4167-4174 (2019).

${ }^{39}$ C. H. Hsu, Y. S. Cho, W. Y. Wu, S. Y. Lien, X. Y. Zhang, W. Z. Zhu, S. Zhang, and S. Y. Chen, Nanoscale Res. Lett. 14, 139 (2019).

${ }^{40}$ K. Kim, O. N. Pierron, and S. Graham, J. Appl. Phys. 125, 045301 (2019).

${ }^{41}$ A. K. Singh, K. Adstedt, B. Brown, P. M. Singh, and S. Graham, ACS Appl, Mater. Interfaces 11, 7498-7509 (2019).

${ }^{42}$ R. H. Temperton, A. Gibson, and J. N. O’Shea, Phys. Chem. Chem. Phys. 21, 1393-1398 (2019).

${ }^{43}$ C.-H. Hsu, C.-W. Huang, Y.-S. Cho, W.-Y. Wu, D.-S. Wuu, X.-Y. Zhang, W.-Z. Zhu, S.-Y. Lien, and C.-S. Ye, Surf. Coat. Technol. 358, 968-975 (2019).

${ }^{44}$ S. K. Vishwanath, H. Woo, and S. Jeon, Nanotechnology 29, 235202 (2018).

${ }^{45}$ M. Putkonen, P. Sippola, L. Svärd, T. Sajavaara, J. Vartiainen, I. Buchanan, U. Forsström, P. Simell, and T. Tammelin, Philos. Trans. R. Soc., A 376, 20170037 (2018).

${ }^{46}$ G. P. Gakis, H. Vergnes, E. Scheid, C. Vahlas, A. G. Boudouvis, and B. Caussat, Chem. Eng. Sci. 195, 399-412 (2019).

${ }^{47}$ A. Lale, E. Scheid, F. Cristiano, L. Datas, B. Reig, J. Launay, and P. Temple-Boyer, Thin Solid Films 666, 20-27 (2018).

${ }^{48}$ R. Pietruszka, B. S. Witkowski, S. Zimowski, T. Stapinski, and M. Godlewski, Thin Solid Films 709, 138191 (2020).

${ }^{49}$ D. Hiller, P. Hönicke, and D. König, Sol. Energy Mater. Sol. Cells 215, 110654 (2020).
${ }^{50}$ F. Mattelaer, M. Van Daele, M. M. Minjauw, M. Nisula, S. D. Elliott, T. Sajavaara, J. Dendooven, and C. Detavernier, Chem. Mater. 32, 4152-4165 (2020).

${ }^{51}$ J. C. Goodrich, T. G. Farinha, L. Ju, A. J. Howzen, A. Kundu, O. N. Ogidi-Ekoko, J. J. Wierer, N. Tansu, and N. C. Strandwitz, J. Cryst. Growth 536, 125568 (2020).

${ }^{52}$ J. G. Baker, J. R. Schneider, J. A. Raiford, C. d. Paula, and S. F. Bent, Chem. Mater. 32, 1925-1936 (2020).

${ }^{53}$ W. Cong, Z. Li, K. Cao, G. Feng, and R. Chen, Chem. Eng. Sci. 217, 115513 (2020).

${ }^{54}$ Q. Deng, C. Tian, and Z. Luo, Ionics 26, 1805-1812 (2020).

${ }^{55}$ C. Prapaipong, D. Boonyawan, C. Umongno, S. Choopun, and P. Ruankham, Mater. Today: Proc. 17, 1521-1530 (2019).

${ }^{56}$ J. Laube, D. Nübling, H. Beh, S. Gutsch, D. Hiller, and M. Zacharias, Thin Solid Films 603, 377-381 (2016).

${ }^{57}$ V. Lujala, J. Skarp, M. Tammenmaa, and T. Suntola, Appl. Surf. Sci. 82-83, 34-40 (1994).

${ }^{58}$ E. B. Yousfi, J. Fouache, and D. Lincot, Appl. Surf. Sci. 153, 223-234 (2000)

${ }^{59}$ A. Yamada, B. Sang, and M. Konagai, Appl. Surf. Sci. 112, 216-222 (1997).

${ }^{60}$ H.-R. An, S.-H. Baek, I.-K. Park, and H.-J. Ahn, Korean J. Mater. Res. 23, 469-475 (2013).

${ }^{61}$ E. B. Yousfi, B. Weinberger, F. Donsanti, P. Cowache, and D. Lincot, Thin Solid Films 387, 29-32 (2001).

${ }^{62}$ H. Makino, A. Miyake, T. Yamada, N. Yamamoto, and T. Yamamoto, Thin Solid Films 517, 3138-3142 (2009).

${ }^{63}$ P. Ingale, K. Knemeyer, M. Piernavieja Hermida, R. Naumann d'Alnoncourt, A. Thomas, and F. Rosowski, Nanomaterials 10, 981 (2020).

${ }^{64}$ T. Muneshwar and K. Cadien, J. Appl. Phys. 124, 095302 (2018).

${ }^{65}$ T. Tynell and M. Karppinen, Semicond. Sci. Technol. 29, 043001 (2014).

${ }^{66}$ B. Sang and M. Konagai, Jpn. J. Appl. Phys., Part 2 35, L602-L605 (1996).

${ }^{67}$ S. K. Kim, C. S. Hwang, S. H. K. Park, and S. J. Yun, Thin Solid Films 478, 103-108 (2005).

${ }^{68}$ S. H. K. Park, C. S. Hwang, H. S. Kwack, J. H. Lee, and H. Y. Chu, Electrochem. Solid-State Lett. 9, 299-301 (2006).

${ }^{69}$ J. Lim and C. Lee, Thin Solid Films 515, 3335-3338 (2007).

${ }^{70}$ E. Guziewicz, I. A. Kowalik, M. Godlewski, K. Kopalko, V. Osinniy, A. Wójcik, S. Yatsunenko, E. Łusakowska, W. Paszkowicz, and M. Guziewicz, J. Appl. Phys. 103, 033515 (2008).

${ }^{71}$ S. Jeon, S. Bang, S. Lee, S. Kwon, W. Jeong, H. Jeon, H. J. Chang, and H.-H. Park, J. Electrochem. Soc. 155, H738 (2008).

${ }^{72}$ S.-Y. Pung, K.-L. Choy, X. Hou, and C. Shan, Nanotechnology 19, 435609 (2008).

${ }^{73}$ A. Miyake, T. Yamada, H. Makino, N. Yamamoto, and T. Yamamoto, Thin Solid Films 517, 3130-3133 (2009).

${ }^{74}$ T. Krajewski, E. Guziewicz, M. Godlewski, L. Wachnicki, I. A. Kowalik, A. Wojcik-Glodowska, M. Lukasiewicz, K. Kopalko, V. Osinniy, and M. Guziewicz, Microelectron. J. 40, 293-295 (2009).

${ }^{75}$ P. C. Rowlette, C. G. Allen, O. B. Bromley, A. E. Dubetz, and C. A. Wolden, Chem. Vap. Deposition 15, 15-20 (2009).

${ }^{76}$ Y.-T. Lin, P.-H. Chung, H.-W. Lai, H.-L. Su, D.-Y. Lyu, K.-Y. Yen, T.-Y. Lin, C.-Y. Kung, and J.-R. Gong, Appl. Surf. Sci. 256, 819-822 (2009).

${ }^{77}$ S.-K. Kwon, D.-W. Kim, Y.-H. Jung, and B.-J. Lee, J. Korean Phys. Soc. 55, 999 1004 (2009).

${ }^{78}$ G. Luka, T. Krajewski, L. Wachnicki, B. Witkowski, E. Lusakowska, W. Paszkowicz, E. Guziewicz, and M. Godlewski, Phys. Status Solidi A 207, 1568-1571 (2010).

${ }^{79}$ E. Guziewicz, M. Godlewski, T. A. Krajewski, Ł. Wachnicki, G. Łuka, J. Z. Domagała, W. Paszkowicz, B. J. Kowalski, B. S. Witkowski, A. Dużyńska, and A. Suchocki, Phys. Status Solidi B 247, 1611-1615 (2010).

${ }^{80}$ D. Kim, H. Kang, J.-M. Kim, and H. Kim, Appl. Surf. Sci. 257, 3776-3779 (2011).

${ }^{81}$ J. T. Tanskanen, J. R. Bakke, T. A. Pakkanen, and S. F. Bent, J. Vac. Sci. Technol., A 29, 031507 (2011).

${ }^{82}$ E. Janocha and C. Pettenkofer, Appl. Surf. Sci. 257, 10031-10035 (2011). 
${ }^{83}$ K. Tapily, D. Gu, H. Baumgart, G. Namkoong, D. Stegall, and A. A. Elmustafa, Semicond. Sci. Technol. 26, 115005 (2011).

${ }^{84}$ K. Pradhan and P. F. Lyman, ECS Trans. 41, 247-253 (2019).

${ }^{85}$ A. Illiberi, F. Roozeboom, and P. Poodt, ACS Appl. Mater. Interfaces 4, 268-272 (2012).

${ }^{86}$ M. B. M. Mousa, C. J. Oldham, J. S. Jur, and G. N. Parsons, J. Vac. Sci. Technol., A 30, 01A155 (2012).
${ }^{87}$ H.-W. Huang, W.-C. Chang, S.-J. Lin, and Y.-L. Chueh, J. Appl. Phys. 112, 124102 (2012).

${ }^{88}$ A. Di Mauro, C. Farrugia, S. Abela, P. Refalo, M. Grech, L. Falqui, V. Privitera, and G. Impellizzeri, Mater. Sci. Semicond. Process. 118, 105214 (2020).

${ }^{89}$ V. Miikkulainen, M. Leskelä, M. Ritala, and R. L. Puurunen, J. Appl. Phys. 113, 021301 (2013). 